\title{
Literatura pornográfica en CALi: CUERPO Y CIUDAD EN LA NARRATIVA DE Hernán Hoyos ${ }^{1}$
}

\author{
PORNOGRAPHIC LITERATURE IN CALI: THE BODY AND \\ THE CITY IN HERNÁN HOYOS NARRATIVE
}

Por: Carolina Gutiérrez Ramírez*

* Magister en Estudios de la Cultura (Mención Literatura Hispanoamericana). Historiadora de la Universidad del Valle. Miembro de grupo Nación/Cultur grapo muy_caro@yahoo.es

Recibido: 8 de marzo de 2016 - Aprobado: 9 de junio de 2016

\section{RESUMEN}

El presente artículo propone un acercamiento al contexto de la ciudad de Cali en las décadas de 1960 y 1970, con la finalidad de dar cuenta de la cultura editorial en lo referente a lo que se podría denominar como el «devenir pornográfico», es decir, una serie de crónicas gráficas, cartillas y revistas pornográficas que circularon en la región y que fueron el preámbulo de los libros pornográficos del escritor caleño Hernán Hoyos, razón de ser de este texto. Por lo tanto, después de recopilar y revisar la totalidad de la obra del autor, se escogieron los textos que retratan la ciudad y que cristalizan la descripción que se lleva a cabo del cuerpo. A partir de allí se realiza un análisis temático de los libros que se consideraron relevantes y que, posiblemente, generaron momentos de sentido en los lectores de la época a través de las representaciones y referencias a lo local y a la corporalidad que se plasma en la narrativa del escritor vallecaucano.

Palabras clave: pornografía, ciudad, literatura marginal, cuerpo y sexo.

\begin{abstract}
This article proposes an approach to the context of the city of Cali in the decades of 1960 and 1970, with the purpose of accounting the publishing culture in terms of what could be called the «pornographic becoming», it refers to a series of graphic chronicles, pamphlets and pornographic magazines that circulated in the region and were the preamble of the pornographic books written by the 'caleño' ${ }^{2}$ writer Hernan Hoyos, which are the foundation of this text. Therefore, after collecting and reviewing the entire author's works, there were chosen the texts that portray the city and crystallize the description that is carried out of the human body. From there, a thematic analysis is done of the books that were considered relevant and that possibly generated moments of feeling in the readers of the time through the representations and references to local and physicality that is reflected in the narrative of the 'vallecaucano's ${ }^{3}$ writer.
\end{abstract}

Key words: pornography, city, marginal literature, body and sex.

Artículo de investigación tipo 2: de reflexión según clasificación de culo es el resultado un apar ciudad y pornogra fia: Génesis de la novela pornográfica en Cali do para optar presentatulo de historiar el la Universidad del Valle.

${ }^{2}$ Caleño is a term that refers to people that are from Cali, Colombia.

${ }^{3}$ Vallecaucano is a term that refers to people that are from the department of Valle del Cauca, Colombia. 


\section{Introducción}

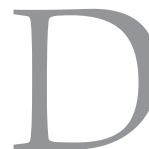

urante la década de 1960, en el espacio urbano de la ciudad de Cali, empezaron a circular revistas, crónicas gráficas y literatura de alto contenido sexual. Este fenómeno era novedoso para la ciudad, y se debía, en gran parte, a una serie de factores políticos, sociales y culturales que coincidieron y posibilitaron la circulación del material pornográfico, entendido este como obras artísticas y literarias de carácter abiertamente obsceno (Diccionario de la Lengua Española, 1992). La violencia de la época, las migraciones del campo hacia las principales ciudades del país, la inestabilidad política, el impulso económico de la región, como también los movimientos culturales y la novedad que, en general, invadió a la ciudad, incidió en el comercio, consumo y, tiempo después, elaboración, de la literatura pornográfica en Cali. Es por ello, entonces, que en Primeros pasos de la pornografía en Cali: de la crónica gráfica a la novela porno se realiza un acercamiento a los diferentes procesos que atravesó la ciudad y que coadyuvaron a que se fundamentara en términos materiales la cultura editorial porno. Interesa en este primer momento comprender e identificar las formas de producción y comercio del material pornográfico, para después dar cuenta de los sectores de repliegue y circulación de este tipo de texto que cimentaría, en los primeros años de la década de 1960, un circuito del libro porno. En efecto, durante la década de 1960 y el inicio del decenio siguiente, la vida cotidiana de la ciudad se trastocó por los impulsos particulares que trajeron consigo la compra, distribución y venta de los libros pornográficos. Debido a esto se tendrán en cuenta fuentes primarias como entrevistas a libreros reconocidos de la época y, al mismo tiempo se valorarán las columnas de opinión de periódicos de la región en los que se percibe el clima que generó la circulación de textos pornográficos en zonas precisas de la localidad. Un novedoso y transgresor género se incorporó al comercio habitual de la región y le confirió a la ciudad nuevos ritmos y peculiares formas de entender la vida cotidiana.

Después de las revistas pornográficas que llegaron a la ciudad provenientes de países vecinos, fue un escritor caleño el que capitalizó el boom pornográfico que se vivió en la ciudad: Hernán Hoyos. Sus relatos recrearon espacios urbanos y prácticas sexuales típicas de la sociedad caleña de esa época; con el tiempo la conexión ciudad/sexo se convirtió en el referente de las novelas del autor caleño y por ello, sus novelas pueden ser leídas como un sistema de representación de la ciudad, el cuerpo y el placer sexual. Debido a ello en La narrativa de Hernán Hoyos: descripción del cuerpo y de la ciudad se problematiza y reflexiona sobre este tipo de representación y los eventuales momentos de sobreidentificación que pudieron generar estos libros en el público lector de 
${ }^{4} \mathrm{De}$ hecho La industria pornográfica - que dicho sea de paso eviden ció el proceso de secularización perceptible en la sociedad caleña - puso en manos del caleño de los decenios de 1960 y 1970 diferentes publicaciones, propias publicaciones, propias o foráneas, que fueron consumidas en un primer momento por los vecinos inmediatos de centro de la ciudad, los estratos populares: San Nicolás, Barrio Obrero, Piloto y Sucre Para luego ser los habitantes de los barrios adyacentes a estos primeros los que se desplazaron a comprar el novedoso material: Guayaquil Bretaña y Cristóbal Colón (Ulloa, 1992).

${ }^{5}$ Alejandro Ulloa se refiere en constantes ocasiones a los estudios que sobre este aspecto ha realizado Harold Martínez en los que el autor destaca dos hechos económicos y políticos que influyeron en los procesos que vivieron ciudades como Cali. El primero de carácter 'externo' en el que hace 'exusión a la 'repartición alusion a la repartición del mun y la división nal del trabajo que durante este periodo asignaría su pape a nuestro país como productor de bienes de consumo y consumidor endeudado de bienes de capital. El segundo ascapital. El segundo aspecto interno en el que se forzó la migración las grandes urbes a partir del conflicto agrario y la lucha por la tierra en los campos colombianos y que explica el autor, desembocaría en untor, desembocarín en capital en las ciudades: se habitaba construyendo (Ulloa, 1992). la época. Asimismo, la presencia de la literatura pornográfica en la ciudad supuso un cambio gradual en las costumbres lectoras de la época; la lectura que se propicia en estos libros genera un espacio de referencialidad en el que se transgreden paradigmas y se forjan imaginarios sobre el devenir sexual de la sociedad. Para este cometido se tuvieron en cuenta algunas obras del autor, a saber Ron, ginger y limón (1962), Las muchachas pobres (1970), El tumbalocas (1972) y La reina y el mariposo (1974), que resultaron relevantes porque en ellas se percibe la intención de retratar la ciudad en tanto sujeto vivo y, por otro lado, también prevalece un afán documentalista sobre el cuerpo y las prácticas sexuales de la comunidad caleña.

\section{Primeros pasos de la pornografía en Cali: de la crónica gráfica a la novela porno}

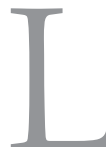
a década de 1960 y el principio del periodo siguiente se caracterizaron por imprimirle a la sociedad caleña un ritmo distinto al habitual. Este ritmo estaba unido a los procesos económicos, sociales y culturales que estaba experimentando la ciudad de Cali y que, paulatinamente, coadyuvaron a que surgieran novedosas experiencias y expectativas en el submundo que era para entonces la cultura editorial porno.

La cultura urbana de la pornografía condensó el proceso de la revolución cultural de la década de 1960 en la capital vallecaucana (Sánchez, 2011). Conviene tener muy en cuenta que todos estos factores se materializaron en Cali a partir de los imaginarios regentes en el ámbito de la sexualidad, los mass media, la industrialización y, en general, los umbrales de la vida pública y privada que se fueron desplazando en el panorama internacional. El material pornográfico de hecho logró en un primer momento encauzarse, distribuirse y comercializarse en sectores específicos de la ciudad; luego, como veremos, sus espacios de comercialización fueron otros ${ }^{4}$.

Como se ha señalado reiteradamente, entre 1950 y 1970 se dio en la ciudad lo que algunos estudiosos han denominado la segunda modernización ${ }^{5}$ (Hoyos H., 2010), esta época estuvo caracterizada por grandes inversiones en el espacio público: construcción de avenidas y puentes elevados, mini rascacielos que empezaron a erigirse en el centro de la ciudad, como también sedes de bancos, industrias, corporaciones y demás que, sin lugar a duda, trastocaban el paisaje usual de la región. Se dio una franca tendencia estructural hacia la urbanización que impulsaba la cultura del consumo, que se vio tan férreamente fortalecida en esta época. Algunos documentos lo registraron así: 
En 1960 los rasgos del progreso caleño eran evidentes. La construcción creció significativamente (...) aparecieron en el centro los rascacielos, edificios de más de diez pisos como el Edmond Zaccour y el Suramericana de Seguros. La Plaza de Caycedo se 'pobló' con el Colombiana de Seguros, el Cemento del Valle, el Banco de la República, el Edificio Sierra, el Ulpiano Lloreda, el Banco de Bogotá y el Hotel Nueva York, cuando apenas diez años antes solo existían dos edificios comerciales de más de dos pisos (Benítez, 1997, p. 32).

El centro de Cali y sus barrios cercanos fueron utilizados como punta de lanza en este impulso económico que el sector empresarial daba a la ciudad. El barrio 'El vallano' o barrio 'San Nicolás' fue escogido como asiento para las tipografías dedicadas a la impresión de periódicos, revistas y semanarios (Vásquez, 2009). También fue escogido para la instalación de fábricas que estuvieron habitadas en su mayoría por obreros. Por un lado la empresa Carvajal S.A. inició sus labores en la carrera $5^{\mathrm{a}}$ con calle 15 en el centro de la ciudad, como simple papelería y distribuidora de textos escolares. Por el otro, el diario El País, que desde 1950 se había ubicado en la carrera 5a con calle 10, a partir de 1970 empleó el sistema off-set de impresión que permitia mayor rapidez y calidad imprimir un gravamen superior de textos ${ }^{6}$ (Biblioteca Departamental Jorge Garcés Borrero, 1998). De allí que para esta época se disparara en el sector, la producción de impresos y demás material de índole tipográfica, como ha señalado Leonardo Vásquez, hijo del reconocido librero de la ciudad Orlando Vásquez (Vásquez, 2009).

Estas nuevas estructuras convivían con una amalgama de personajes variopintos que habían llegado a la ciudad a causa del proceso de violencia colombiano, lo que hacía que estas dinámicas fueran mucho más complejas y particulares $^{7}$. Entonces los procesos económicos de la ciudad concatenados con las dinámicas culturales del tejido social de la época, confluyeron en nuevas necesidades y nuevas expectativas tanto de los nativos de la ciudad como de los recién llegados del campo y de otros destinos del país. Aquí los medios técnicos con los que contaba la ciudad propiciaron nuevas experiencias. Los mismos impulsos económicos y sociales transformaron incesantemente el mundo que lo rodea, para bien o para mal, transformando las vidas interiores de los hombres y las mujeres que lo habitan y lo mantienen en movimiento (Berman, 1982, p. 367). Herbert Marcuse, cuando reflexiona sobre las necesidades individuales en detrimento de las aspiraciones y expectativas, expresa lo siguiente: "el crecimiento de las fuerzas productivas sugiere posibilidades de
${ }^{6}$ Es válido recordar que Pablo Borrero, Ignacio Rengifo e Ignacio Guerrero habían donado con anterioridad sus máquinas para que la Conferencia de San Vicente de Paul iniciará la enseñanza de artes gráficas. Todos estos datos son recogidos del fondo 'Recuerdos de mi barrio' que reposa en la Sala Valle del Cauca de la Biblioteca Departamental Jorge Garcés Borrero (Cali-Colombia).

${ }^{7}$ En esa línea Luz Mery Giraldo en el texto Fin de siglo: narrativa codombiana reflexiona lombiana reflexiona
sobre los procesos culturales persistentes en Cali y otras grandes ciudades durante esta época: "para la década de 1970 , Bogotá, Medellín, Cali y Barranquilla son ciudades en las que conviven sectores sociales de muy diversos orígenes culturales y con diferentes y contradictorias actitudes frente al Estado, la Iglesia la familia, la educación los medios masivos y e mismo espacio urbano"
(Giraldo, 1995, p. 14). 
${ }^{8}$ En esta parte del texto el autor realiza una entrevista al empresario Mario Hincapié de Intermedio Editores en la que el entrevistado advierte que al consumidor de esta época había que ponerle el material de manera explícita para que sea por medio de los sentidos que se incline por cierto tipo de libros populares que sobreabundaron en estos año (Chavarro, 1992, p. 40). libertad humana muy diferentes" (Marcuse, 1969, p. 13). Sin embargo, el autor irá más allá y determinará que en la sociedad de la abundancia dos dinámicas se moverán en terreno propio: el aumento en la producción de mercancías y, en segundo grado, el incremento en la explotación productiva que lograrán unirse e impregnar todas las dimensiones de la existencia pública y privada (Marcuse, 1969, p. 15). La vida cotidiana de la década de 1960, pero sobre todo, de los primeros años de la década siguiente, estuvo fuertemente marcada por estos procesos que desde las artes gráficas impulsaban nuevas técnicas que facilitaron el tránsito del libro en la ciudad. Hubo un relevo económico de sectores emergentes - como el de las tipografías de la ciudad que ascendieron con fuerza, escalando posiciones (Ulloa, 1992, p. 612).

De allí que como toda mercancía, el libro circulaba y delineaba sus recorridos. Luis Alfonso Chavarro, en su estudio sobre la circulación del libro de publicación masiva en la ciudad, determina que hubo desde esta época y en grado ascendente un circuito o red del libro que se percibió en el mapa local: quioscos, puestos de revistas y, lo que el autor ha denominado 'corredores del Centro', en los que predominaba el tipo de literatura popular. También el autor aludió a librerías menores en el centro de la ciudad al lado de la Plaza de Caicedo o cerca a la Gobernación, algunas de más cobertura en la denominada zona del 'Cali viejo' (Chavarro, 1992, p. 39). Chavarro señala que en estos espacios el tipo de libros que él ha denominado literatura de consolación causó gran impacto en el sector editorial al ser de fácil venta por su bajo costo y deleitable temática que no dejaba de ofrecer una nueva forma de placer al lector de la época ${ }^{8}$. Esta literatura de consolación, aludiendo a la literatura popular que recrea la vida sexual de sus personajes, tomará un nuevo impulso a partir de las tecnologías que confluían en el sector. Razón tiene Michel de Certeau cuando reflexiona sobre el espacio 'corporal' y el sistema mecánico: "esta maquinaria transforma los cuerpos individuales en un cuerpo social (...) la imprenta representa esta articulación del texto sobre el cuerpo por medio de la escritura" (De Certeau, 2000, p. 129). Sin embargo, las publicaciones de las novelas pornográficas de Hernán Hoyos no suponían ningún refinamiento en la materialidad del libro; durante gran parte de la década de 1960 se trató de publicaciones que vivían en el reino de los libros de saldo o en el depósito de los libros raros (Ramírez, 2011). Esta edición económica supuso escasa atención en la redacción del texto, en su coherencia y ortografía, en ella también se evidencia la poca exigencia en cuanto a la preparación del estilo del formato y, por último, aunque más revelador, el material que se utilizará en la caratula y contracaratula (cartón de baja gama) delata las necesidades 
comerciales de los editores de la época, el imaginario que subyace en torno a él como género menor y, en general, el estatus underground que le da el editor al libro de esta naturaleza. Los autores del texto La ceremonia del porno se han percatado de este estatus que ha envestido al libro porno:

El porno se concibe y consume en formatos rudimentarios reducidos a la mínima expresión narrativa y formal (...) ver porno es fácil: quizá no haya nada más llevadero y más fácil entre los estímulos que ofrece nuestra sociedad del espectáculo (...) se suele pensar en el porno como género perezoso y grado cero de la representación, como el más rudimentario de los géneros de ficción al que pueda optar el más rudimentario de los consumidores (Barba \& Montes, 2007 , p. 17).

Similar a lo que ocurría en la Francia decimonónica con la Biblioteca azul, la lectura de los denominados libros rústicos quedaba descalificada para las élites que condenaban sus textos como carentes de clase, despreciando así su forma descuidada (Chartier, 2002, p. 161). Así, esta literatura desde los medios técnicos, volvía a ser clasificada como perteneciente a 'cierto tipo'. Desde la opinión pública se logró identificarla como subgénero, literatura de masas o literatura marginal:

Lo que a nosotros nos admira no es tanto que haya individuos que viven exclusivamente del mercadeo de la pornografía, con libros marginales, revistas, estampas, almanaques, grabados, colecciones, fotos, laminas, etc., que colocan por millares entre las juventudes de los dos sexos y un poco también entre unos cuantos viejos verdes, (...) Lo que es más admirable, es que nuestra sociedad - que se dice cristiana a carta cabal - no se haya querido dar cuenta de la podredumbre que se ha colocado por todas partes, y nada haya hecho por desterrarla o contenerla. Basta con salir a los tendidos o ventas de publicaciones que existen en cualquier parte, y en sus principales calles y plazas, en los sitios de vecindad de colegios y de templos, para enterarse como se venden, se cambian, se alquilan, se facilitan y en todas formas se divulgan las más abyectas publicaciones del crudo y bochornoso sexualismo impúdico (El Crisol, 1968, p. 4)

Aunque la cita es larga, en esta columna de opinión de la época se advierte sobre la proliferación del material pornográfico en la Cali de aquellos años, 
${ }^{9}$ Pese al aura peyorativa que rodea a este género, algunos autores han advertido que este tipo de literatura considerada "marginal» reproduce el auténtico juego intertextual de la socieda ya que las interacciones entre lo oral $y$ lo escrit entre lo oral y lo escrito, entre lo letrado y lo iletrado, entre lo visual y lo auditivo y, en conclusión, se podría hablar de un juego intercultura que se haría más visible que en cualquier otra parcela de lo liteotra parcela de lo literario (García de Enterría, 1995, p. 10) asimismo, es evidente la preocupación de ciertos sectores de la sociedad -en este caso la élite cultural- por el consumo y el aparente beneplácito de los y las lectoras locales. Este clima de pública desaprobación, pero de camuflado consumo crean las bases de lo que se ha denominado como literatura marginal, entendida esta como una categoría literaria ubicada al margen o en la frontera de la literatura «tradicional» (Castrillón, 2013). Chartier reflexiona sobre esta partición tradicional que opone lo culto y lo popular, la última entendida como la cultura de la mayoría y que puede identificarse para nuestro caso como el conjunto de textos vendidos mediante venta ambulante; en ellos se reproduce una serie de situaciones, lugares y representaciones típicas de la cultura popular. Sumado a esto, el autor define lo popular en contraposición con aquello que no es, así lo popular tendrá un cuerpo bien diferenciado: la literatura erudita y letrada (Chartier, 2002, p. 3).

En efecto esas representaciones que no son ni eruditas ni letradas ${ }^{9}$ empezaron a circular con mayor impulso debido a la reciente utilización de nuevas tecnologías tipográficas y de impresión en el casco urbano. La ciudad empezaba a convivir con material pornográfico y este más profusamente invadió quioscos, corredores urbanos y pequeñas librerías del centro de la ciudad, tal como advierte Elí Sánchez, reconocido librero de la época (Sánchez, 2011). Así la atmósfera citadina se trastocaba con el ritmo habitual que proporcionaba el material corruptor vuelto lícito, conocido y tolerado. Ruwen Ogien reflexiona sobre los síntomas que son notorios en la sociedad que convive con la pornografía: "Las cosas comienzan a torcerse a partir del momento en que, gracias a los medios de difusión modernos, tales representaciones comienzan a circular fuera del pequeño círculo, y los más pobres también pueden disfrutarlas" (Ogien, 2005, p. 73).

Y, sin embargo, con la literatura pornográfica, masificada y consumida, el tránsito urbano se vio trastocado por las dinámicas que su comercio suponía (Vásquez, 2009). Recordemos ahora que en un principio los libros de Hernán Hoyos eran un asunto de ocultación y camufle ya que la pornografía se consideraba un problema social, un fenómeno amorfo de la cultura de masas; la pornografía había florecido por lo bajo. Este tipo de literatura colocaba en circulación los bajos fondos de la sociedad caleña: las prostitutas, el homosexual, el proxeneta, la lesbiana, la ninfómana y los demás. Así, conviene señalar, la pornografía fue considerada una amenaza y era aún más grave cuando se retrataba detalladamente el comportamiento obsceno de la población que era al mismo tiempo su consumidora. 
Luego, de 1965 a 1975 las novelas pornográficas, escritas sobre personajes de la ciudad y ofrecidas por vendedores ambulantes del centro de la ciudad, abandonaron los anaqueles ocultos del librero de Santa Rosa de Lima y se acomodaron en los andenes y escaparates del centro urbano, tal y como mencionaron Ramón Ramírez (2011) y Elí Sánchez (2011) en diferentes entrevistas. De esa manera, al tránsito citadino se le adhirió un nuevo producto que fue ganando espacio: el espacio del porno. Sobre este espacio algunos autores advierten:

El porno no es una cosa, una imagen, sino la «representación visual» de esa imagen y la experiencia de su recepción. Y sólo puede darse si el sujeto y el objeto se encuentran en el lugar adecuado: el de la «violación deliberada» del tabú. En último término, el porno es la experiencia de una representación en un sitio: el sitio de la transgresión (Barba \& Montes, 2007, p. 63).

Al incluir estos hábitos de lectura (o al menos la rutina de su observancia en el mercado y la posibilidad de su compra) y las dinámicas características de la convivencia con este novedoso y polémico material cultural, la ciudad y sus habitantes incursionaban en una esfera que tenía al sexo como opción de entretenimiento y de esparcimiento cultural: "la ciudad mezcla hábitos, percepciones, historias (...) es precisamente en la fusión de todas estas intermediaciones y costuras, como va aflorando la propia urbanidad o personalidad colectiva de la ciudad" (Silva, 1992, p. 62).

Es válido recordar que la permanencia de este material en el mercado obedecía no solo al objetivo económico del sector editorial que se vio significativamente beneficiado por el libro pornográfico ni, por otro lado, gracias a las presunciones literarias de Hernán Hoyos que lograba transgredir -y capitalizar- el tabú sexual por medio de sus representaciones, sino, sobre todo, a la creciente demanda que este tipo de libro provocaba. Esta venta estrepitosa de material pornográfico (revistas, crónicas, relatos, novelas y demás) evidenciaba los estragos que causaron la revolución sexual de la década de 1960 -que se dio de forma mesurada y parcial en la ciudad- en la mentalidad de la clase popular caleña, principal compradora y vecina interesada del gran despliegue comercial de literatura sicalíptica:

En el curso de la era pornográfica, en lo que va de 1840 a 1960 , representaciones de todo tipo proliferaron de un modo inconcebible 
y a un ritmo acelerado tanto en cantidad como en medios de comunicación. Los libros impresos siguieron el mismo destino, junto a cada uno de los medios de comunicación inventados durante este periodo (...) la tendencia fue hacia una diseminación más amplia de aún más amplias representaciones que así saturaban la cultura de palabras e imágenes (Kendrick, 1995, p. 284).

Es así, entonces, que de 1965 a 1975 los libreros de la ciudad constatan el éxito en ventas de este género (Vásquez, 2009). Por un lado, durante estos años se incrementaron las ediciones de los libros de Hernán Hoyos y se reeditaron sus obras publicadas años atrás. Asimismo su repertorio también se había diversificado, consolidando un grupo social literario que confluyó alrededor del porno: monjas, empleadas domésticas, curas, profesores, enfermeras, reinas comunitarias, chóferes, prostitutas, vigilantes, hacendados, meseras, pintores, estudiantes, talabarteros, tenderos y demás, cuyos dos únicos puntos de encuentro son el desenfreno sexual y su ciudad de residencia. De esa manera se lleva a cabo en la obra de Hoyos una prosopografía de la vida sexual de la ciudad: la pulsión sexual del médico interno, de la institutriz, del vigilante, del profesor universitario, del párroco local, del panadero y otros. Publicación tras publicación, el imaginario de una comunidad porno local se fue configurando en los relatos que retrataba en su obra Hernán Hoyos.

Después de una amplia pesquisa documental entre las principales librerías y el centro de venta de libros de segunda 'El parque Santa Rosa de Lima', se recopilaron algunos de los libros, revistas y crónicas gráficas de temática sexual que más circularon en corredores, quioscos y librerías de la ciudad entre 1960 a 1975. El cuadro 1 señala y describe este material:

Interesa en este momento no perder de vista que, percibido de forma general, un ajuar de textos de marcado contenido sexual circularon en el centro caleño $y$, en tanto eso, se puede percibir que hubo un circuito de comunicación del libro, ya que los impresos -entendidos como objetos- tienden a dinamizar los discursos, cristalizar las prácticas, romper paradigmas y crear imaginarios sobre las temáticas a las que se refieren.

\section{La narrativa de Hernán Hoyos: descripción del cuerpo y de la ciudad}

ernán Hoyos, en la totalidad de sus publicaciones, propone
testimonios, reportajes, diarios íntimos, entrevistas, anecdotarios,
novelas y crónicas de la vida sexual de Cali que como entrega final 


\begin{tabular}{|c|c|c|c|c|c|c|c|c|c|c|c|c|c|c|c|c|c|}
\hline 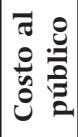 & $\begin{array}{c}8 \\
i \\
i \\
\dot{n}\end{array}$ & $\begin{array}{l}8 \\
\dot{+} \\
\dot{n}\end{array}$ & \begin{tabular}{l|}
8 \\
0 \\
1 \\
5 \\
5
\end{tabular} & $\begin{array}{c}8 \\
\vdots \\
\vdots \\
\vdots \\
5\end{array}$ & $\begin{array}{l}8 \\
0 \\
\infty \\
\vec{\infty}\end{array}$ & 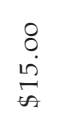 & $\begin{array}{l}8 \\
0 \\
\dot{w} \\
0 \\
0\end{array}$ & $\begin{array}{l}8 \\
8 \\
\dot{1} \\
\dot{5}\end{array}$ & $\begin{array}{l}8 \\
\dot{0} \\
i \\
\infty\end{array}$ & $\begin{array}{l}8 \\
\stackrel{0}{1} \\
-1 \\
0\end{array}$ & $\begin{array}{l}8 \\
\stackrel{8}{0} \\
\vec{n}\end{array}$ & $\left|\begin{array}{cc}0 & 8 \\
0 & 0 \\
n & 0 \\
w & 0 \\
n & n\end{array}\right|$ & $\begin{array}{l}8 \\
\stackrel{0}{1} \\
\dot{n}\end{array}$ & $\begin{array}{l}8 \\
0 \\
i \\
i \\
\theta\end{array}$ & $\begin{array}{cc}8 & 0 \\
0 & \vdots \\
0 & 0 \\
0 & 0 \\
\infty & \infty\end{array}$ & 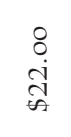 & $\begin{array}{l}8 \\
\text { ma } \\
\text { sin }\end{array}$ \\
\hline 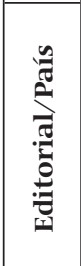 & 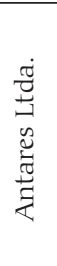 & 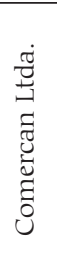 & 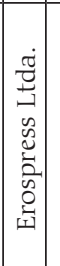 & 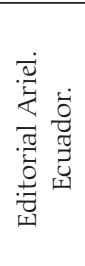 & 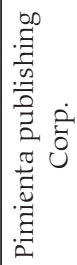 & 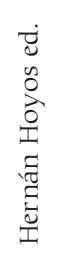 & 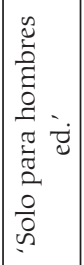 & 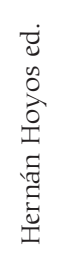 & 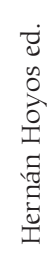 & 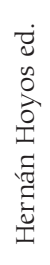 & 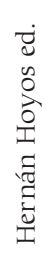 & 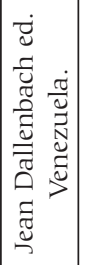 & 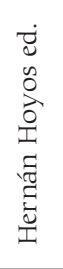 & 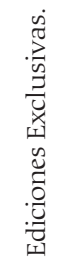 & 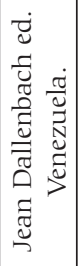 & 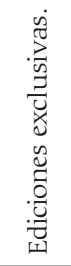 & 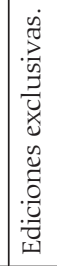 \\
\hline
\end{tabular}

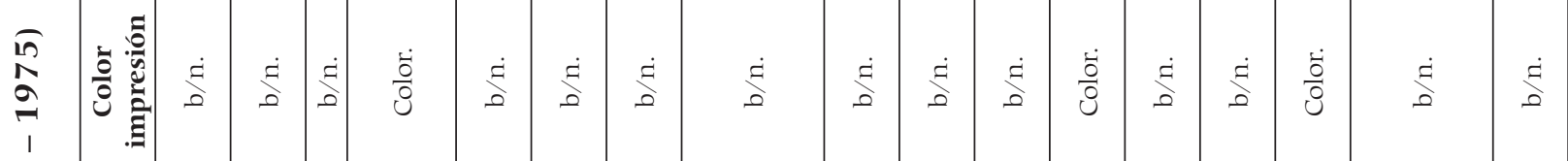

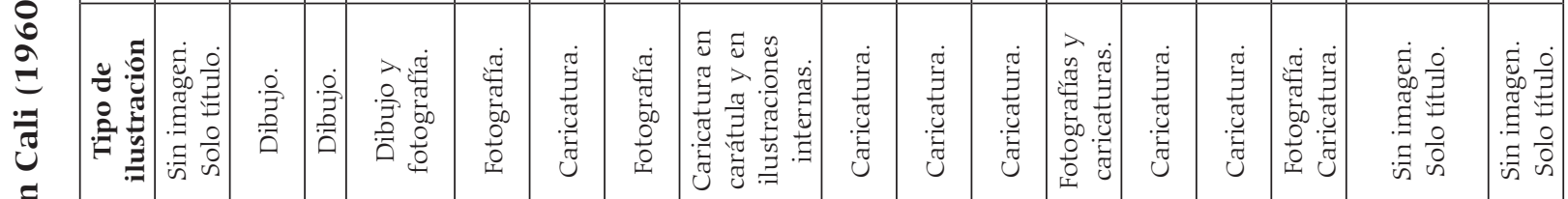

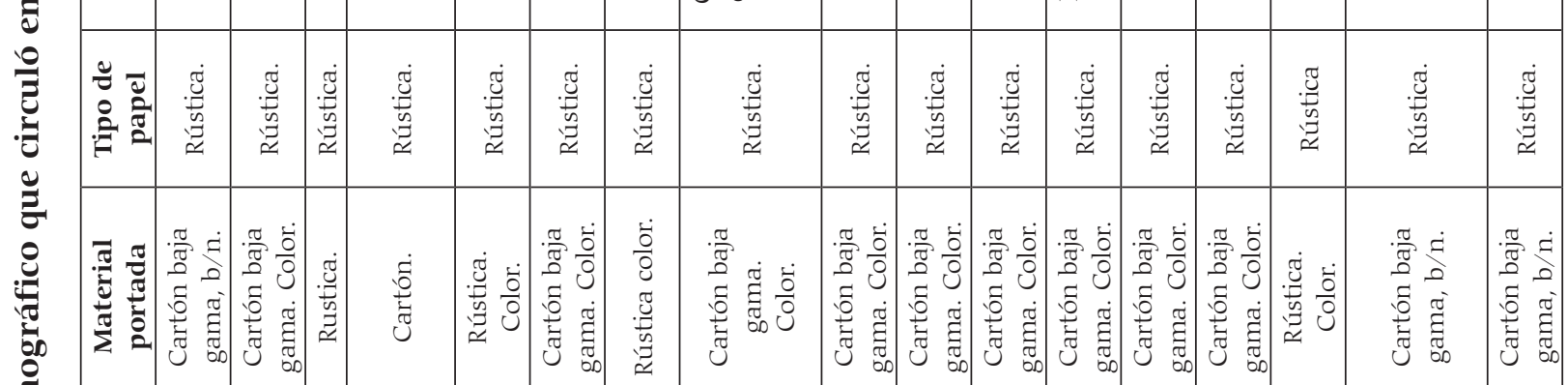

\begin{tabular}{|c|c|c|c|c|c|c|c|c|c|c|c|c|c|c|c|c|c|}
\hline 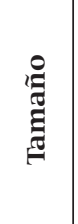 & 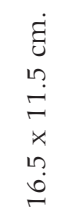 & 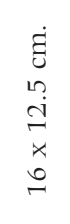 & 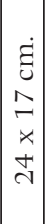 & $\begin{array}{l}\dot{\Xi} \\
\vec{d} \\
\dot{x} \\
\vec{n}\end{array}$ & 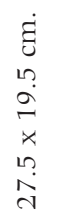 & 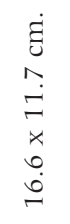 & 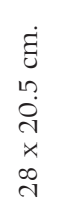 & 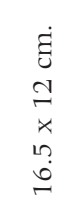 & 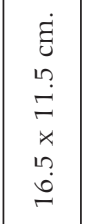 & 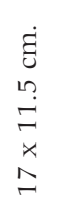 & 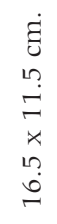 & 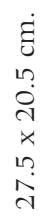 & 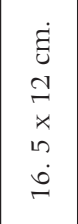 & 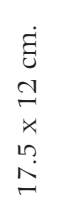 & 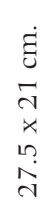 & 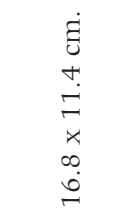 & 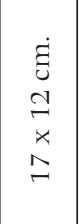 \\
\hline 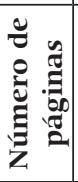 & oे & J & ○ & तु & 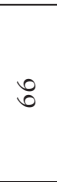 & ટ્సે & సె & రి & ర్ర & 犬ે & $\stackrel{3}{0}$ & ชิ & $\stackrel{\mathbb{I}}{ }$ & $\underset{\sim}{\stackrel{J}{O}}$ & $\hat{\sigma}$ & $\stackrel{0}{ \pm}$ & t \\
\hline 宗 & $\begin{array}{l}\text { त̂ } \\
\text { }\end{array}$ & \begin{tabular}{l}
3 \\
\multirow{2}{2}{} \\
2
\end{tabular} & $\begin{array}{l}\llcorner \\
\vdots \\
\curvearrowright \\
\end{array}$ & $\begin{array}{l}\stackrel{2}{\circ} \\
\stackrel{2}{2}\end{array}$ & $\begin{array}{l}\stackrel{R}{2} \\
\stackrel{2}{\rightarrow}\end{array}$ & $\begin{array}{l}\stackrel{R}{2} \\
\stackrel{2}{\sim}\end{array}$ & $\begin{array}{l}\text { ה } \\
2\end{array}$ & $\stackrel{\pi}{\stackrel{\lambda}{\partial}}$ & 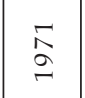 & 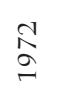 & 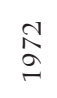 & 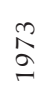 & $\begin{array}{l}\stackrel{n}{2} \\
\stackrel{2}{2}\end{array}$ & 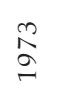 & \begin{tabular}{l}
\multirow{2}{N}{} \\
$\stackrel{2}{\sigma}$
\end{tabular} & $\begin{array}{l}\stackrel{+}{\Delta} \\
\stackrel{2}{\sim}\end{array}$ & 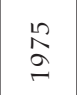 \\
\hline 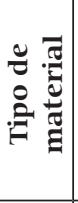 & $\begin{array}{l}\frac{\pi}{\tilde{J}} \\
\tilde{0} \\
z\end{array}$ & 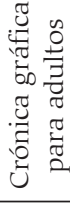 & 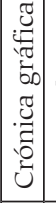 & 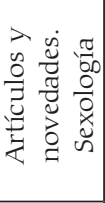 & 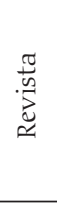 & $\begin{array}{l}\frac{\pi}{2} \\
\tilde{z} \\
z\end{array}$ & 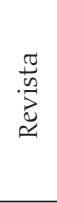 & $\begin{array}{l}\frac{\pi}{\pi} \\
\tilde{z} \\
z\end{array}$ & 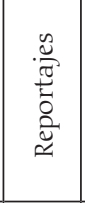 & $\begin{array}{l}\frac{\pi}{\pi} \\
\tilde{z} \\
z\end{array}$ & $\begin{array}{l}\frac{\pi}{\pi} \\
\tilde{z} \\
z\end{array}$ & 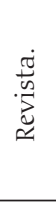 & $\begin{array}{l}\frac{\pi}{0} \\
\tilde{0} \\
z \\
Z\end{array}$ & 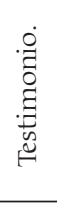 & 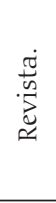 & 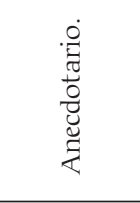 & $\begin{array}{l}\frac{\pi}{0} \\
\text { ठे }\end{array}$ \\
\hline $\begin{array}{l}\frac{\pi}{0} \\
0 \\
\frac{\pi}{0} \\
0 \\
0 \\
\frac{0}{E}\end{array}$ & 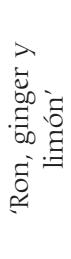 & 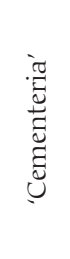 & 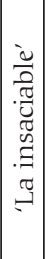 & 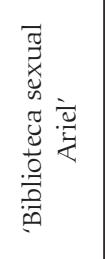 & 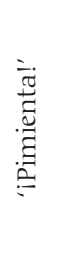 & 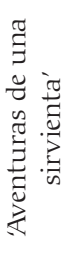 & 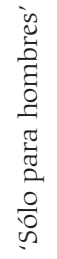 & 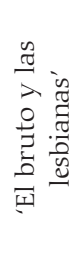 & 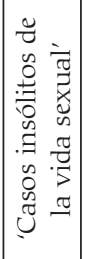 & 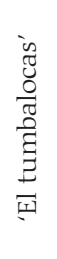 & 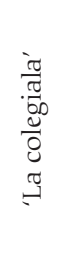 & 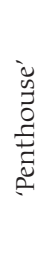 & 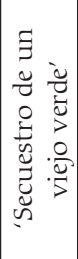 & 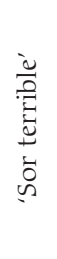 & 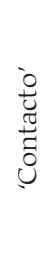 & 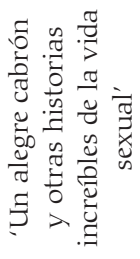 & 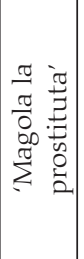 \\
\hline
\end{tabular}


reporta una biblioteca ambulante que tiene como módulo a la ciudad y el disfrute sexual. Sin embargo, debe tenerse en cuenta que los textos también han cimentado un engranaje de la vida sexual de la población caleña y sus referentes urbanos. La forma y el contenido de sus obras hacen hincapié en la vitalidad corporal, la diversidad sexual de la ciudad y el diario vivir de la misma. Es por eso que todas las aventuras sexuales que el autor describe recrean sitios diversos de la ciudad que sirven para dar escena a sus paisajes imaginativos.

De tal manera que se empieza a hacer emergente en la obra del autor caleño una comunidad sexual que suma a su coreografía la variedad de variopintos personajes -de diferentes estratos socioeconómicos, oriundos de otras regiones del país y demás- que solo una ciudad en constante crecimiento y urbanización puede ofrecer. Tal como afirma Jesús-Martín Barbero al referirse a este tipo de ciudades en las que modernización y urbanización han sido, por lo general, procesos desiguales, estas culturas urbanas serán llevadas a cabo en condiciones complejas y en un lapso de tiempo relativamente corto, el autor lo dirá así: "las nuevas musicalidades que nos definen e identifican, las mutaciones deslumbrantes del habla popular, los novedosos mecanismos de resistencia política y de solidaridad social, los lenguajes visuales permanentemente renovados encuentran en estas ciudades su fermento crítico y su mejor espacio de realización" (Martin Barbero, 1994, p. 5).

Hoyos no desprecia la arquitectura de la ciudad ni las condiciones de miseria en que viven algunos de sus personajes. De allí que se mencionen sectores tuguriales de la ciudad, habitaciones roídas por la pobreza y por la falta de higiene, utensilios deteriorados que hacen parte del diario vivir $y$, en general, detalles que delatan la miseria de sus personajes. A modo de ejemplo en Las muchachas pobres se narra: "Don Rafael estaba acostado, con las piernas cubiertas por una cobija de parches. Tenía las mejillas arrugadas y terrosas (...) La muchacha miró la ollita aplastada en la cual se calentaba la leche sobre el fogón de petróleo. Preparó una taza descarachada y una azucarera de otro color..." (Hoyos H. , 1970, p. 10). Asimismo no descartará la descripción de las viviendas populares, allí se describen casas de bahareque amplias y largas que, por la penuria económica de sus habitantes, se han venido a menos:

Alejandro abrió los ojos y miró el cielo raso sucio y descarachado. Bostezó, retiró las cobijas raídas y comenzó a retorcer todo su cuerpo (...) Tenía puesta una pijama sucia y vieja. Se aproximó a 
la rota maleta que estaba en un asiento y extrajo un cepillo para dientes. Se encaminó hacia la puerta, la abrió con lentitud y espió cuidadosamente. Era cosa muy seria la patrona cuando alguien le debía (Hoyos H., Ron, ginger y limón, 1962, p. 7).

Algo parecido sucede con los espacios interiores que construye Hernán Hoyos. Sus dormitorios populares primarán por la austeridad y el amontonamiento paulatino de cachivaches en el que una sábana en malas condiciones separará el cuarto paterno de los demás. Allí el hacinamiento lindará escandalosamente con el incesto. Asimismo el espacio para la higiene de la familia estaba violentado por la necesidad de ingresos económicos de la casa paterna: los hijos deberán compartir sus espacios de aseo con solitarios jubilados, enfermeras beatas o zapateros ebrios a los que se arrenda una habitación en esos hogares pobres del centro de la ciudad. Situación reiterada que se describirá en el relato sobre la convivencia de los hogares humildes de la ciudad: "Daniel entró al inodoro (...) y dejando la puerta abierta se puso a orinar. La señorita Anuncia estaba lavando ropa en el lavadero del rincón (...) Había mirado a Daniel de reojo. Escuchó el chorro del muchacho y haciéndose la tonta vino hacia el inodoro con ropa húmeda en la mano" (Hoyos H. , 1972, p. 8). En este pasaje se percibe la descripción del cuerpo y de los lugares; prevalece un afán por rastrear y dar cuenta de los mínimos detalles de la realidad con la finalidad -al parecer- de demostrar que la versión que ofrece el autor es fidedigna. En las descripciones de Hoyos el interior de la casa popular, a modo de ejemplo, siempre se ve desde la calle, las puertas abiertas ponían en evidencia la pobreza de sus propietarios. Y así, dejaba el autor en algunos de sus libros, el 'cuarto de San Alejo' o la denominada 'pieza de los cachivaches' para el encuentro furtivo de las parejas en busca de penumbra. De la misma manera Hoyos recrea detenidamente las formas de convivencia de los lugares en los que la armonía se dificulta: la vecindad del barrio popular, el humilde ancianato céntrico, el prostíbulo que es a la vez restaurante y hospedaje durante el día, los cuartos compartidos en el convento o el inquilinato de estrato bajo ${ }^{10}$.

Así, el encuentro cotidiano, el escándalo nocturno, la celebración sabatina o el desplazarse en el transporte público, son tópicos que Hoyos referencia hasta la saciedad; los días, las direcciones, los referentes citadinos, los parques conocidos, los restaurantes célebres o las fondas tradicionales, entran en la prosa del autor. Este detalle, al parecer, contribuyó a los efectos de realidad a los que se refiere Roger Chartier: "así ligado a lugares concretos, conocidos o conocibles, el relato gana una fuerza de autenticidad que contribuye a darle la
${ }^{10}$ En efecto esa cotidianidad se percibe en varios momentos de $\mathrm{La}$ reina y el mariposo: "En las casas de inquilinato es muy importante irla bien con todos los vecinos, porque de lo contrario uno se expone a que en la cocipone a que en la cocinquilina tiene su mesita y fogón, la vecina disgustada le eche sal l chocolate, o al café, o tierra a la roben los calzones el jabón" (Hoyos H. , 1974 , p. 59). 
apariencia de verdadero" (Chartier, 2002, p. 184). Certeza que, sin embargo, nos refiere a otra constatación: era un espacio particular de la sociedad el que estaba siendo captado por el autor, codificado por él. La agrupación de sus relatos evidencian las formas de sociabilidad que durante 1960 y principios de la década siguiente persistieron en la ciudad. Situación que coincide con las apreciaciones que Walter Benjamin ha realizado sobre los escritores y aquello que escriben: "la novela representa una muestra (...) en la que el autor se amolda a la sociedad, traen algo así como un punto de vista ordenativo sobre el caos de la producción" (Benjamin, 1998, p. 82). Los relatos de Hoyos se acercaban más a la realidad al describir minuciosamente aspectos mínimos del diario vivir, esta peculiaridad conjugada con la franqueza del lenguaje empleado por el autor creó un efecto de proximidad entre obra y lector.

De 1973 a 1975 este material se había convertido en el material de consulta y referencia de las estrategias lúdico-amorosas de la capital vallecaucana (Vásquez, 2009). Como bien lo explica Robert Darnton en el texto El coloquio de los lectores: "el sexo es especialmente bueno para pensar: se le puede acomodar en esquemas, que descubren relaciones inesperadas y definen fronteras vagas" (Darnton, 2003, p. 61). Así las prácticas sexuales y la dinámica propia de los tabúes culturales habían permitido que a su alrededor surgieran materiales que abordaran la vida íntima de los habitantes de la ciudad. La pornografía de la época suministró un gran arsenal para igualar los estratos de la sociedad caleña, al desnudar a todos los personajes de sus distinciones sociales, la pornografía expuso similitudes: todos los lectores (as) son excitables y todos buscaban, con estrategias particulares, el placer sexual. Aunque cambiase el entorno que el autor retrataba, su temática literaria mantenía una cierta coherencia; en sus relatos todos los personajes son corruptibles: las nobles señoritas exigen favores sexuales de sus criados, los sacerdotes consiguen beneficios carnales de confundidas campesinas recién llegadas del campo, profesores omnipotentes que, bajo el pretexto de instruir en educación sexual, se exhiben frente a sus estudiantes; entonces los párrocos siempre abusarán de sus feligresas en el confesionario, la dueña de casa siempre tendrá un carácter corrompido, la anciana quejumbrosa utilizará su bajo perfil para suministrarse placer de confundidos monaguillos. Es necesario ahora indicar que, a medida que se van desarrollando sus novelas van, asimismo, superándose las inhibiciones anteriores: con cada publicación hay un tabú superado.

Todos estos temas se volvieron efectivos cuando son transformados por el autor en relatos urbanos en los que Hoyos deja de lado la corrupción y la 
desigualdad que priman en estas prácticas sexuales. La estrategia, según parece, consiste en hacer creíble el relato y para ello, como se advertía anteriormente, se vale de la descripción de sitios populares y de la descripción minuciosa de los órganos sexuales de los personajes. Para 1989, Huberto Batis en el libro Estética de lo obsceno había destacado este artificio: "el escritor de hoy quiere describir, supongamos, el pene de un personaje que entra en la vagina de una mujer; pero esta penetración debe ser literariamente distinta de cualquier otra penetración que jamás haya sido descrita" (Batis, 1989, p. 35).

La prolijidad y extensión de la obra de Hoyos se debe en gran parte no solo a la solicitud de los lectores sino al valor simbólico que estos le proporcionaban a los relatos. El lector contribuyó a la construcción de las imágenes y escenas que Hoyos plantea, cada uno le agregará su referente personal. Señalamiento que coincide con los planteamientos de Raman Selden: "no se podrá hablar del sentido de un texto sin considerar la contribución del lector" (Selden, 1989, p. 149), el autor explica que el lector habitualmente actúa sobre el material que lee y le da sentido: los textos literarios siempre tienen «huecos» que solo el lector puede llenar con su propia experiencia (1989, p. 130). De allí que valoremos significativamente los códigos culturales en los que estuvieron inscritos autor, obra y lector. Esta reciprocidad planteó significados, referentes, cuestionamientos o valoraciones sobre los sitios retratados y las prácticas que se realizaban en los relatos de Hoyos. El texto no fue un instrumento estático, él dialoga incesantemente con el lector de aquella época. Selden también reflexiona sobre el dinamismo del mensaje escrito: "una obra literaria no representa objetos, se refiere al mundo extraliterario seleccionando ciertas normas, sistemas de valores o «concepciones del mundo». Dichas normas son conceptos de realidad que ayudan a los seres humanos a extraer algún sentido del caos de su experiencia" (1989, p. 134). Es por ello que lo leído en las obras de Hoyos, la descripción que de la ciudad se hace $y$, finalmente, las propias experiencias del lector implicado generan una cadena de sentido que solidifica y dan autoridad a la versión de realidad que se ha plasmado en la obra del autor vallecaucano. Entonces el texto, según algunos autores, se presenta como producto de una lectura y por ello como construcción de su lector (Chartier, 2002, p. 38). Hay un asunto de identidad que es susceptible cuando estas lecturas se realizan: "utilizamos la obra literaria para simbolizarnos y, finalmente, para repetirnos. Refundimos el texto con la finalidad de descubrir nuestras propias estrategias características para enfrentar los deseos y los miedos profundos que dan forma a nuestras vidas psíquicas" (Selden, 1989, p. 146). 
Existieron, al parecer, dos factores en relación con el sexo y la literatura que incidieron categóricamente para que la literatura pornográfica se radicara en la ciudad. El primero, es su temática claramente escandalosa y el tipo de relato sugestivo, franco y popular que presentaba, es probable que tal condición resultara atractiva para el lector de la época. Al igual que Roger Chartier, creemos que la especificidad de este tipo de libros reside más en el modo de su apropiación que en la estricta sociología de su público (Chartier, 2002, p. 162). Aunque debe tenerse en cuenta que prevalece un apasionado primitivismo en los lectores de estos libros, ya que en estos textos prima la descripción del cuerpo por encima de otra forma representativa, lo que permite al lector asomarse como lo haría un voyeur a la intimidad ajena. Por otro lado, como segundo factor, la ausencia de relatos autóctonos que retrataran prácticas sexuales, anécdotas barriales y demás pasajes divertidos sobre la vida íntima de personajes de la región, fue un aspecto aún más significativo. A nuestro modo de ver estos dos factores serán determinantes para que se produjera el efecto de reconocimiento y asimilación que tuvieron estos tipos de relatos que podríamos denominar, al no encontrar algo mejor, como porno-regionalistas.

Por lo tanto, es posible que para comienzos de la década de 1960 los libros pornográficos de Hernán Hoyos se hayan convertido en una pieza relevante de la cultura literaria de la ciudad. Asimismo, para esta época ya no serán una lectura exclusivamente de la clase popular. Su amplia circulación nos indica que su presencia en la ciudad es firme y numerosa (Vásquez, 2009). Buena parte del aura de la ciudad se debe a la interacción entre sus calles, sus bares, su gente y el mundo editorial que fomentaba cierto tipo de lecturas urbanas. De allí que para 1975 la literatura pornográfica producida en la región ya se hubiera consolidado aunque, por otro lado, la industria pornográfica en torno a ella aún se estaba erigiendo. Por ello, la literatura sensual y de ocio empezó a circular de manera más espontánea y no soslayadamente como en los primeros años de la década de 1960, crecía conforme al interés de un público lector que apenas se acomodaba y se estructuraba al pulso de crecimiento que el mercado tipográfico regional proponía. Sin duda, el porno empezó a percibirse entre las colecciones y el mercado editorial de Cali de forma natural y espontánea por la eventual acogida de un viandante que no fue reticente.

\section{BIBLIOGRAFÍA}

Archivos de consulta

Archivo Concejo Municipal de Santiago de Cali. Actas y decretos. (1960 - 1975).

Archivo Departamento Administrativo de Planeación Municipal. Área mapoteca. 
Archivo Histórico de Cali. Fondo judicial.

Biblioteca Departamental. Área hemeroteca.

Centro de Documentación Regional. Banco de la República.

Revistas y Cartillas

Crónica gráfica 'Cementeria'.

Crónica gráfica 'La insaciable'.

'Crónica gráfica para adultos'.

Revista 'Contacto'.

Revista 'Penthouse'.

Revista 'Play boy'.

Revista para adultos 'Pimienta!'.

Revista 'Solo para adultos'.

Revista 'Visión'.

Prensa

Diario El insurgente (1960 - 1973).

Diario despertar vallecaucano (1955 - 1965).

Diario El relator (1958 - 1960).

Diario El expreso (1960- 1970).

Totalidad de la Obra de Hernán Hoyos

Benítez, E. V. (1997). Asi es Cali. El País, pág. 32.

Giraldo, L. M. (1995). Fin de siglo: narrativa colombiana. Cali: Crítica.

Berman, M. (1982). Todo lo sólido se desvanece en el aire. Madrid: Siglo XXI.

Marcuse, H. (1969). Un ensayo sobre la liberación. México: Editorial Muñoz.

Ulloa, A. (1992). La salsa en Cali. Cali: Universidad del Valle.

Chavarro, L. A. (1992). La circulación del conocimiento a través del libro de publicación masiva y su incidencia socio-cultural en Cali. Trabajo de grado (Sociologo). Santiago de Cali: Universidad del Valle. Facultad de Ciencias Sociales y Económicas. Departamento de Sociologia.

De Certeau, M. (2000). La invención de lo cotidiano. 1. Artes de hacer. México: Universidad Iberoamericana.

Ramírez, R. (29 de 01 de 2011). propietario de 'Librería Universitaria'. (D. C. Gutiérrez, entrevistador). 
Barba, A., \& Montes, J. (2007). La ceremonia del porno. Barcelona: Editorial Anagrama.

Chartier, R. (2002). El mundo como representación. Historia cultural: entre práctica y representación. Barcelona: Gedisa.

El Crisol. (1968). Divulgación pornográfica. El crisol No. 6099 , 4.

Ogien, R. (2005). Pensar la pornografía. Barcelona: Editorial Paidós.

Sánchez, E. (30 de 04 de 2011). Comerciante dedicado a la venta de revistas para adultos. (D. C. Gutierrez, Entrevistador).

Silva, A. (1992). Imaginarios urbanos. Bogotá: Tercer Mundo.

Kendrick, W. (1995). El museo secreto. La pornografía en la cultura moderna. Bogotá: Tercer Mundo Editores.

Martín Barbero, J. (1994). Mediaciones urbanas y nuevos escenarios de comunicación. Caracas: Fundarte.

Hoyos, H. (1962). Ron, ginger y limón. Bogotá: Talleres Gráficos Antares.

Hoyos, H. (1970). Las muchachas pobres. Cali: Ediciones Exclusivas.

Hoyos, H. (1972). El tumbalocas. Cali: Ediciones Exclusivas.

Hoyos, H. (1974). La reina y el mariposo. Cali: Ediciones Exclusivas.

Benjamin, W. (1998). Imaginación y sociedad. Madrid: Editorial Taurus.

Darnton, R. (2003). El coloquio de los lectores: ensayos sobre autores, manuscritos, editores y lectores. México: Fondo de Cultura Económica.

Batis, H. (1989). Estética de lo obsceno (y otras exploraciones pornotópicas). México: Universidad Autónoma del Estado de México.

Selden, R. (1989). La teoría literaria contemporánea. Barcelona: Editorial Ariel.

Biblioteca Departamental Jorge Garcés Borrero. (1998). Fondo 'Recuerdos de mi Barrio'. Cali: Sala Valle del Cauca.

Hoyos, H. (20 de 10 de 2010). Escritor. (D. C. Gutiérrez, entrevistador)

Vásquez, L. (31 de 10 de 2009). Sobre las primeras tipografías y librerías. (D. C. Gutiérrez, entrevistador).

Castrillón, C. A. (2013). Marginalia III: relecturas del canon literario. Armenia: Universidad del Quindio.

García de Enterría, M. C. (1995). Literatura popular. Anthropos No. 166/167.

Diccionario de la Lengua Española. (1992). Madrid: Real Academia Española. 

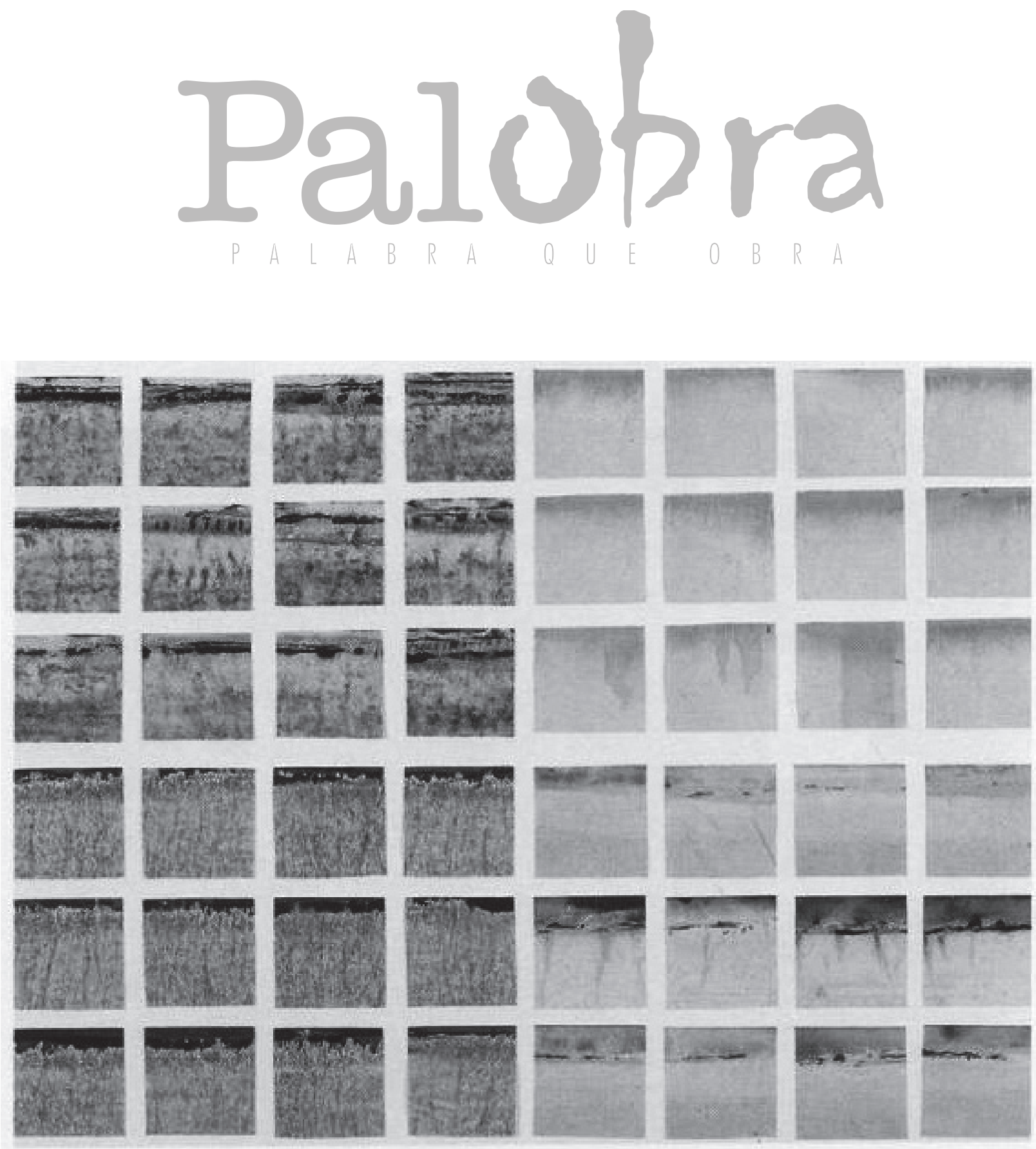

Serie de Cinco. 1992.

Papel fotográfico y papel crepé. 